\title{
NIETZSCHE E O SURREALISMO: UMA LEITURA DE “PERSPECTIVAS”, DE SÉRGIO BUARQUE DE HOLANDA
}

\section{NIETZSCHE AND SURREALISM: A READING OF SÉRGIO BUARQUE DE HOLANDA'S PERSPECTIVAS}

\author{
Guilherme Pinheiro Pacheco ${ }^{1}$ \\ Instituto de Estudos Brasileiros
}

\begin{abstract}
RESUMO
"Perspectivas" (1925), o denso e instigante ensaio de Sérgio Buarque de Holanda, revela-se um texto marcado por uma inflexão reflexiva, mas que não abre mão de um registro textual que tangencia o poético. Publicado na revista Estética (1924-1925)- da qual Sérgio Buarque era um dos idealizadores e redatores - e no calor da hora modernista, as ideias e críticas contundentes ali expressas não encontraram ressonância entre seus pares ou opositores. O escrito permaneceu até certo ponto mudo para a maioria dos seus contemporâneos, mas, contudo, vem despertando cada vez mais a atenção dos estudiosos da obra e do pensamento buarqueano. O presente artigo procura fazer uma leitura desse ensaio, buscando algumas possíveis chaves de leitura, mais especificamente rastreando a presença do pensamento nietzschiano e de concepções surrealistas nas reflexões do então jovem crítico literário.
\end{abstract}

PALAVRAS-CHAVE: Sérgio Buarque de Holanda; Friedrich Nietzsche; Surrealismo; Crítica literária

\begin{abstract}
"Perspectivas" (1925), the dense and thought-provoking essay by Sérgio Buarque de Holanda, reveals itself as a text with a remarkable reflective tone, while not giving up the poetic style. Published in the journal "Estética" (1924-1925) - of which Sérgio Buarque was one of the founders and writers - in the heat of the Modernist movement, the ideas and blunt criticism there expressed did not resonate with his partners and antagonists. The work remained muffled to a certain degree for the majority of his contemporaries; however, it has been progressively drawing the attention of scholars of the work and thought of Buarque de Holanda. The current article aims to offer a reading of this essay, searching for possible key subjects, in special tracking down the presence of the ideas of Nietzsche and Surrealism in the observations of the young critic.
\end{abstract}

KEYWORDS: Sérgio Buarque de Holanda; Friedrich Nietzsche; Surrealism; Literary Criticism.

\section{INTRODUÇÃO}

Se fosse possível adjetivar preliminarmente a participação do autor de "Perspectivas" (1925) no modernismo, procurando uma qualidade estável ou essencial a seu ato crítico, diríamos que suas análises possuíam certa "sensibilidade sísmica", capaz de registrar tênues movimentos,

\footnotetext{
${ }^{1}$ Mestre em Filosofia, com ênfase em Estudos Brasileiros, pelo Instituto de Estudos Brasileiros, Universidade de São Paulo. E-mail: gui_pacheco88@hotmail.com.
} 
captando diversas ressonâncias literárias. Acrescentemos ainda que seu trabalho beneficiava-se de uma constante colaboração entre sua precoce erudição e certa intuição sui generis.

$\mathrm{Na}$ passagem do primeiro ao segundo periódico modernista, de Klaxon (1922-1923) a Estética (1924-1925), impressiona a relação entre o tempo decorrido e a qualidade e importância das realizações de Sérgio Buarque. O salto executado pelo jovem crítico desconcerta porque, de certa forma, desrespeita a lógica temporal do saber adquirido através do tempo, depurado lentamente. Se na revista paulista ele era um simples representante no Rio de Janeiro, em Estética passa a ser editor do então principal órgão do movimento e colaborador contumaz, intensificando sua intervenção no sentido vertical, acentuando a profundidade de suas reflexões e adensando o teor de suas considerações.

O assombro diante desse episódio nos faz pensar na correspondência entre a trajetória de um indivíduo e a de um movimento artístico amplo, de proporções nacionais. Mas há que se reconhecer a incontornável desproporção entre os dois elementos. Se quiséssemos estudar o modernismo, teríamos que abordar diversas frentes, tratando de cobrir seus diversificados componentes. Tal complexidade exigiria uma multiplicidade de exames, que escapariam ao foco de nossa pesquisa.

Todavia, nos arriscamos a dizer que o período liminar do itinerário do jovem Sérgio Buarque de Holanda encontrou-se, em larga medida, ligado de maneira umbilical ao movimento de 1922. Nos escritos pós-1921, ou seja, posteriores a sua adesão ao modernismo, esta circunstância manifesta-se drasticamente, externando-se através de expressões concretas de sua atuação como sujeito crítico, livre de certas hesitações e pronto para exercer ingerências enfáticas. Conjuntamente, percebemos tratar-se de um intervalo onde o aprendizado e a realização prática dos conhecimentos absorvidos coexistem de forma prolífica.

A observação analítica é um predicado central na crítica literária buarqueana; a ela junta-se a intervenção intencional, o engajamento reflexivo. O crítico equilibra-se entre o ato exegético e a participação militante, tendo que se haver com as solicitações reclamadas por cada uma destas perspectivas. Uma dupla demanda da qual decorre a tensão motora do exercício crítico do jovem Sérgio Buarque, perturbadora de certa postura de neutralidade distanciada, axioma do conceito de crítica literária ideado pelo senso comum.

Klaxon e Estética representaram fases próximas, porém distintas do mesmo movimento literário. As duas revistas foram capazes de expressar novas interpretações, realizando, cada uma a sua maneira, o momento modernista que lhes concernia, desdobramentos afins e contrastantes. $\mathrm{Na}$ passagem de uma para a outra, mantém-se a postura vanguardista, mas com sintomáticas contraposições: entre a contestação iconoclasta de 1922-1923 e a construção meditativa de 19241925; entre a provocação dos klaxistas e a reflexão mais introspectiva e sisuda de Estética; entre a alegria combativa da revista paulista e a sisudez inteligente da revista carioca; enfim, entre a expressão gráfica inovadora de Klaxon e a expressão gráfica sóbria de Estética.

As diligências de crítico literário militante do modernismo moldam e concretizam o primeiro trecho da trajetória intelectual de Sérgio Buarque de Holanda. Trata-se de um período formativo especial, uma vez que forma-se o crítico, o intérprete, mas forma-se igualmente um novo tempo modernista, ramificação plena de possibilidades.

Com o aporte do jovem crítico, o movimento viabilizou a transição que indicava uma relação mais madura com a cultura estrangeira, mais especificamente a europeia. A revista Estética e a atuação de Sérgio Buarque trouxeram uma lição de engenhosa sobriedade neste quesito, descobrindo e aproveitando as potencialidades deste diálogo, sem deixar de respeitar nossas particularidades. 


\section{Manifesto: elogio à noite}

Nas páginas de Klaxon, há a presença de alguns elementos relativamente novos no quadro das ideias e da cultura brasileira. Dentre eles, encontramos referências à psicanálise, teoria que começava a encontrar ressonância no Brasil do começo do século $\mathrm{XX}^{2}$. No artigo-manifesto de apresentação da revista, entrevemos uma primeira alusão às concepções freudianas, apontadas como instrumento de libertação artística: "KLAXON sabe que o laboratório existe. Por isso quer dar leis cientificas à arte; leis sobretudo baseadas nos progressos da psicologia experimental. Abaixo os preconceitos artísticos! Liberdade![...]”"(KLAXON, 2014, p.2)3.

Outro ponto que podemos destacar diz respeito à presença do insólito e do fantástico como tema-procedimento literário. Nas páginas do mensário paulista, algumas peças de ficção flagram o extravasamento do real em direção ao plano do irreal, o extraordinário contaminando, de maneira sub-reptícia, a normalidade cotidiana. Nesse sentido, destacamos duas produções: o conto "A extraordinária história da mulher que se tornou infinita", de Antônio Carlos Couto de Barros (1896-1966)", e a prosa "Antinous (fragmento)", de Sérgio Buarque de Holanda 5 .

Esse direcionamento dos klaxistas está estreitamente vinculado às pesquisas e aos esforços do modernismo de 22 no sentido de uma atualização e de uma modernização da cultura brasileira. A arte e as ideias europeias, sobretudo, forneceram subsídios fundamentais para a ação

2 Ao comentar o contexto da recepção das teorias psicanalíticas no Brasil, Cristiana Facchinetti refere-se à crise provocada pela Primeira Guerra Mundial (1914-1918), que desestabilizou de maneira violenta a imagem que tínhamos da Europa. O modelo de civilização europeu, nossa principal e tradicional referência, vacilava e perdia-se em um surpreendente exemplo de barbárie. Segundo a autora, "quando a sociedade assume a perda da estabilidade das referências e se permite romper com a tradição [...], acaba por se permitir um novo modo de olhar o país. [...] Vai-se alinhavando um discurso encorpante, produtor de singularidade e densidade subjetiva, relacionado à perda das certezas a respeito dos valores, da verdade e do si mesmo, e que acaba por dar origem a um sujeito com uma crise de identidade crônica, resultante da falta de referências externas capazes de servirem de modelo. Por sua vez, é esse o sujeito que pode permitir a validação da psicanálise na sociedade urbana brasileira do início do século XX." (FACCHINETTI, 2003, p. 118-119).

${ }^{3} \mathrm{O}$ artigo está assinado apenas "Da redação". A referências completa está em: Revista Klaxon, n 1, 15 de maio de 1922, p. 2, in: Klaxon: Mensário de Arte Moderna. São Paulo: Imprensa Oficial do Estado de São Paulo, Biblioteca Brasiliana Guita e José Mindlin, 2014.

4 O conto de Couto de Barros narra a história de uma mulher (dona Brazilizia) que, após seu casamento com Adoasto, começa a engordar progressivamente e de maneira ininterrupta. O insólito fenômeno preocupa o marido, que passa a procurar suas causas, em busca da cura que interrompesse a "desastrosa distensão orgânica" (21) de sua mulher. O crescimento desta acompanha o desarranjo do novo lar, que passa a - também progressivamente - se desestruturar. Vendo seu amor diminuir (“Seu amor estava na razão inversa da massa de d. Brazilizia” [p. 20]), e sem encontrar explicações racionais para o estranho acontecimento, Adoasto perde as esperanças e a razão, sendo envolvido paulatinamente pela loucura, que o leva a um colapso mental ao identificar na silhueta da esposa o símbolo matemático do infinito ("Encontrou d. Brazilizia estendida num divã, a cintura apertadíssima, a dividir-lhe o corpo em duas rotundíssimas metades. Contemplando-a, Adoasto teve a impressão de ver um 8 deitado, símbolo do infinito matemático." [p. 21]). Ver: BARROS, A. C. Couto de. "A extraordinária história da mulher que se tornou infinita" [Klaxon, n 8-9, dezembro de 1922 - janeira de 1923] in: Klaxon: Mensário de Arte Moderna. São Paulo: Imprensa Oficial do Estado de São Paulo, Biblioteca Brasiliana Guita e José Mindlin, 2014, p. 20-21.

5 Assim como o conto de Couto de Barros, a prosa de ficção de Sérgio Buarque de Holanda trabalha com elementos que flexionam e distendem a rigidez do real, alcançando situações absurdas através da utilização de técnicas de simultaneidade e do uso humorístico do anacronismo. Em "Antinous", o autor mistura a forma de diálogos a trechos narrativos, descrevendo um cortejo popular que saúda o Imperador Adriano, que aparece de "monóculo, mastigando um enorme havana apagado" (p. 2); na comitiva principal que o acompanha, estão "Tiresias o feiticeiro, Sansone Carrasco, Guildenstein e Rosenkratz e o desembargador Ataulpho de Paiva” (p.2). No choque de temporalidades antípodas, que estrutura toda a narrativa, vemos, por exemplo, o seguinte elogio, feito por um orador ao "Imperador arquiteto", ao "Imperador artista": "Vede esta cidade monstro com seus edifícios, seus arranha-céus, com suas ruas asfaltadas, com seus anúncios, com seus cinemas, seus cartazes... Vede este palácio (Aponta para um palácio que tem aspecto de um formidável queijo de minas). Vede a civilização borborinhante que que enche as nossas ruas, as nossas praças, os nossos boulevards, os nossos...". HOLANDA, Sérgio Buarque de. "Antinous (fragmento)" [Klaxon, $\mathrm{n}^{\circ} 4$, 15 de agosto de 1922] in: Klaxon: Mensário de Arte Moderna. São Paulo: Imprensa Oficial do Estado de São Paulo, Biblioteca Brasiliana Guita e José Mindlin, 2014, p. 1-2. 
renovadora, abrindo caminhos reveladores e, em certos pontos, desconhecidos ou ignorados até então por nossos artistas. Das lições absorvidas naquele momento, os modernistas não desprezaram as sugestões que faziam balançar os alicerces racionalistas, que abriam espaço para a pesquisa do mundo interior do homem e para a desfiguração do mundo exterior ${ }^{6}$.

Cecília de Lara, estudando os traços internacionalistas presentes na revista Klaxon, aponta justamente para as linhas de influências às quais nos referimos. Dentre elas, está a exploração do subconsciente e da angústia, assim como a utilização da deformação e do expressionismo no processo de criação artística. Posturas que, segundo a autora, revelavam uma oposição ao intelectualismo, traduzida em uma atitude "irracionalista, anti-clássica, de mergulho nas profundidades do próprio indivíduo" (LARA, 1972, p. 215-216).

Algumas das reflexões de Rubens Borba de Moraes aproximam-se desse posicionamento, participando das investigações que se aproveitaram das novas perspectivas abertas por Freud (1856-1939) e Bergson (1859-1941). Podemos considerá-las como um elemento de ligação entre o ideário do mensário paulista e o da revista Estética, ambos voltados, em certos pontos, para a exploração dos caminhos velados da psique humana.

Nesse sentido, são significativas as ideias expostas na sexta seção do ensaio "Balanço de fim de século" (1922), publicado no quarto número de Klaxon (15 de agosto de 1922); texto que Rubens Borba reaproveitou, com pequenas alterações, no terceiro capítulo de Domingo dos séculos. Neste, ao considerar certas características da arte e do artista moderno, escreve:

$\mathrm{O}$ artista moderno nem sempre é lógico, racional, porque não é inteligente. É no subconsciente que o poeta, o pintor, o compositor vão buscar a emoção estética. Lá no subconsciente eles encontram sua realidade, a única que lhes importa. A Inteligência, já vimos, enfraquece a sensação; a intuição nunca. Hoje só há uma escola: a personalidade. (MORAES, 2001, p. 32)

É justamente esse capítulo que chama à atenção de Sérgio Buarque de Holanda quando resenha o livro de Rubens Borba em Estética ${ }^{7}$. Na revista carioca, as cogitações psicanalíticas, especialmente aquelas que se referem ao subconsciente ou inconsciente, permanecem como uma via profícua de reflexão.

Rodrigo Melo Franco de Andrade (1898-1969), comentando o "estado do espírito contemporâneo" e as "tendências mais características do pensamento moderno", refere-se a um "eu" instável e constantemente renovado. Para o autor, a persistência entre os escritores modernos de processos subjetivistas estava diretamente relacionada ao comportamento psicológico do homem moderno: "E isso porque a experiência dos psicólogos contemporâneos havendo concluído contra a existência de um eu permanente e inalterável, toda ou quase toda a arte moderna ficou dominada por essa descoberta da fluidez e da mutação incessante da personalidade." (ANDRADE, 2014, p. 295).

No artigo "Sobre a sinceridade" (1925), Prudente de Moraes, neto, ao discutir as ideias de Benjamin Crémieux (1888-1944) a respeito da questão da personalidade na arte, também aborda a problemática do "eu". Discordando de algumas propostas do crítico francês, o diretor de Estética

\footnotetext{
6 Virgílio Noya Pinto, traçando um breve panorama da Europa depois da Primeira Guerra Mundial (1914-1918), aponta para algumas conexões entre as circunstancias histórico-sociais daquele momento e a reação artística por elas suscitadas: "O pós-guerra trouxe uma presença constante de tensão política, social, moral, religiosa; uma inquietude ante o acúmulo de novas questões suscitadas no terreno dos valores filosóficos, psicológicos e estéticos, e uma angústia e busca apaixonada de um ponto de apoio ante a derrocada das mais sólidas construções do passado [...] $\mathrm{Na}$ configuração deste quadro o artista o captou, em toda a sua profundidade e na sua sensibilidade, repudiou o real e o racional buscando, no absurdo e no irracional, a forma de retratar e agredir o mundo que o circundava." (PINTO, 1984, p. 23).

${ }^{7}$ A referência para o texto encontra-se em: HOLANDA, Sérgio Buarque de. "Rubens de Moraes - Domingo dos séculos - 'Cadeia azul', Rio de Janeiro, 1924” in: O Espirito e a Letra: estudos de crítica literária I, 1920-1947. São Paulo: Companhia das Letras, 2005, p. 202-103.
} 
recorre a conceitos psicanalíticos para pensar o fenômeno artístico moderno, que passava a ser investigado com as ferramentas teóricas que a nova disciplina oferecia ${ }^{8}$.

Para o jovem autor, era preciso relevar a importância do papel do inconsciente na criação artística: "Porque si não há nada na imaginação que não tenha estado no inconsciente, há muita cousa no inconsciente que por si nunca chegará à imaginação. É preciso atirar-lhes uma corda por onde possam subir." (MORAES, 2014, p. 161).

As especulações direcionadas para a subjetividade do sujeito, marcadamente através das questões levantadas pela teoria freudiana, revelam-se de maneira mais aprofundadas em suas considerações. A partir das possibilidades que tal perspectiva interpretativa oferecia, Prudente sugere uma apreciação que compreende as origens da arte vinculadas às regiões reveladas pelo estudo do inconsciente:

A arte nasceu provavelmente com a reprodução dos sonhos. Depois não eram mais os
sonhos, quero dizer, os fatos sonhados que se reproduziam, mas o próprio estado de
sonho que se tentava prolongar mesmo fora do sono e que produzia novos sonhos
imediatamente fixados em arte. Isso se dá sempre que a arte se separa nitidamente da
história. O poeta conta o que sonha. É um sonhador. Ora, sonho= utopia, desejo
impossível. Um desejo difícil que finalmente se realiza, parece um sonho. (MORAES, 2014, p.
161)

Podemos dizer que a pesquisa do inconsciente - emergente no momento em que o fraccionamento do sujeito moderno era percebido de maneira contundente - direcionava-se para fronteiras limítrofes onde a provisória linha que separa a realidade da imaginação apagava-se, lá onde a rigidez das certezas vacilava e onde as "verdades" passavam a ser questionadas.

O sonho seria a via por excelência de acesso aos espaços mais recônditos da mente humana, a "corda" por onde subiriam as "cousas" do inconsciente, vistas como material de trabalho do artista-sonhador. Essa posição, que defendia o inconsciente como fonte de criação artística, é também uma afirmação das convicções surrealistas de Prudente de Moraes.

O "apelo à liberdade total do espírito" proposto pelo surrealismo, com sua "afirmação de que a vida e a poesias estão 'alhures', e que é preciso conquistá-las, perigosamente" (RAYMOND, 1997, p. 253-254), também encontrou ressonância nos desejos e anseios do outro jovem diretor de Estética. No último número da revista ( $\mathrm{n}^{\circ} 3$, abril-junho de 1925), Sérgio Buarque de Holanda publica um texto veemente, ensaio que possui um pulso diferente dos textos que havia escrito até então.

Em "Perspectivas" (1925), a aproximação com o surrealismo foi reconhecida pelo autor, fazendo parte de "um clima meio surrealista" compartilhado sobretudo com o amigo Prudente de

\footnotetext{
8 “A psicanálise equipara a arte ao sonho. Ela é a consequência da luta dos desejos e tendências instintivas e as forças de toda espécie - a censura - que tentam reprimi-los. Para se manifestarem, esses desejos esperam o relaxamento do sono ou disfarçam-se. Um dos meios de se disfarçar é a arte. Sublimação. Isto é, aproveitamento por um esforço consciente para fins elevados." (MORAES, 2014, p. 160).

${ }_{9}^{9}$ Podemos lembrar que a revista Estética é considerada uma das primeiras revistas brasileiras a receber e repercutir as propostas surrealistas, sobretudo aquelas que foram alinhavadas no Manifesto do Surrealismo (1924). Comentando a presença do surrealismo na revista carioca, Valentin Facioli escreve: “O surrealismo foi percebido logo em 1924 por um grupo que se reuniu no Rio de Janeiro entorno da revista Estética [...] Os dois jovens diretores, Prudente de Moraes, neto, e Sérgio Buarque de Holanda, defenderam o surrealismo e polemizaram contra seus detratores, que já apareceram quase instantaneamente [...]”. (FACIOLI, 1999, p. 298). Sérgio C. de Franceschi Lima, historiando os momentos exemplares da afirmação do surrealismo no Brasil, anota: "Prudente de Moraes, neto e Sérgio Buarque de Holanda lançam a revista Estética, com o propósito de ser a primeira revista de crítica do 'modernismo brasileiro'. Estética é também a primeira publicação a acolher positivamente o Surrealismo no Brasil, não nas equivocações de uma 'escola literária' mas sim, e desde já, enquanto movimento e 'perspectiva' inaugural de um novo espírito" (LIMA, 1998, p. 161).
} 
Moraes ${ }^{10}$. No ensaio, ela pode ser percebida na poética que convoca o homem à retomada de sua condição de "sonhador definitivo", na crítica à sua acomodação e à sua moderação, que o mantinha cativo de "uma imperiosa necessidade prática" (BRETON, 2012, p. 220-221). Enfim, a afinidade com o surrealismo revela-se na rebelião contra o "reinado da lógica" e do "racionalismo absoluto", perspectivas que restringiam a experiência humana ${ }^{11}$ - elementos que já se encontravam presentes no "Manifesto do Surrealismo" (1924), de André Breton (1896-1966).

Buarque de Holanda mostra-se sensível à crítica ao sujeito moderno e à postura surrealista que incitava o homem a uma impetuosa oposição às formas limitadoras da vida. A partir delas, adotará uma postura de desconfiança e de desaprovação das grandezas e das mediocridades da representação que fazemos do mundo, da "suave e engenhosa caligrafia que os homens inventaram para substituir o desenho rígido e anguloso das cousas" (HOLANDA, 2005, p. 215) ${ }^{12}$. Nesse sentido, é categórico ao escrever:

\begin{abstract}
Eu, Sérgio Buarque de Holanda, acho indiscutível que em todas as cousas exista um limite, um termo, além do qual elas perdem sua instabilidade, que é uma condição de vida, para se instalarem confortavelmente no que só por eufemismo chamamos sua expressão e que na realidade é menos que seu reflexo. Só os pensamentos já vividos, os que se podem considerar não em sua duração, mas objetivamente e já dissecados, encontram um termo. Quero dizer: esse termo só coexiste com o ponto de ruptura com a vida. (HOLANDA, 2005, p. 214)
\end{abstract}

Na passagem, há uma rigidez de expressão que se equilibra com a reflexão aguda, ambas encadeadas em uma argumentação muito bem realizada. Como observou João Kennedy Eugênio, o jovem autor procurava valorizar a vida no que ela possuía de incerteza e risco, atitude que revelava o vitalismo que nutria as convicções buarqueanas à época. Ainda segundo Eugênio, essa posição manifestava-se na crítica a todo tipo de representação fixa do real, especialmente as direcionadas às formas cristalizadas da arte e da literatura, assim com aquelas voltadas à linguagem e à palavra (EUGÊENIO, 2008, p. 439-440).

Seria preciso, portanto, encontrar maneiras de se viver que resistissem à estabilização empobrecedora da vida, que possibilitassem ao homem atingir as experiências em sua essência dinâmica e instável, naquilo que elas apresentavam de imponderáveis. Ao equilíbrio e à serenidade artificiosa criada pelas representações, encaradas como negação da vida, Sérgio Buarque propões expedições radicais por domínios incertos, pelas paisagens pouco exploradas dos sonhos:

\footnotetext{
${ }^{10}$ Em entrevista cedida à Maria Célia Leonel, em julho de 1975, Sérgio Buarque revela o ambiente referencial no qual o texto "Perspectivas" (1925) foi composto: "É uma coisa meio surrealista. Tive uma discussão muito grande com o Prudente sobre a primeira frase, que é um pouco confusa mesmo. Começamos a escrever cartas surrealistas, conforme a receita de Breton”. A partir dessa declaração, a entrevistadora pergunta se o artigo surgiu por influência de Breton, tendo como resposta: "Creio que um pouco. Independentemente do manifesto, havia um clima meio surrealista. [...]” (LEONEL, 1984b, p. 178).

${ }^{11}$ Breton, no "Manifesto do Surrealismo" (1924), descreve da seguinte maneira a situação contra a qual o surrealismo pretendia rebelar-se: "Vivemos ainda no reinado da lógica, eis, bem entendido, aonde eu queria chegar. Mas os processos lógicos, de nossos dias, só se aplicam à resolução de problemas de interesse secundário. O racionalismo absoluto que continua na moda só permite considerar fatos de pequena relevância de nossa experiência. Os fins lógicos, ao contrário, nos escapam. É inútil acrescentar que à própria experiência foram assinalados limites. Ela gira dentro de uma gaiola de onde é, cada vez, mais difícil sair. Apoia-se, também ela, na utilidade imediata e é observada pelo bom-senso." (BRETON, 2012, p. 226).

${ }_{12}$ Nessa passagem, Sérgio Buarque lembra que "a resistência ao milagre caracteriza um estado de espírito que não é bem o dos contemporâneos. Já se ousa pretender mesmo e sem escândalo, que a mediocridade ou a grandeza de nosso mundo visível só dependem da representação que nós nos fazemos dele, da qualidade dessa representação. Nada nos constrange a que nos fiemos por completo na suave e engenhosa caligrafia que os homens inventaram para substituir o desenho rígido e anguloso das cousas." (HOLANDA, 2005, p. 215).
} 


\begin{abstract}
Hoje mais do que nunca toda arte poética há de ser principalmente - por quase nada eu diria apenas - uma declaração dos direitos do Sonho. Depois de tantos séculos em que os homens mais honestos se compraziam em escamotear o melhor da realidade, em nome da realidade temos de procurar o paraíso nas regiões inexploradas. Resta-nos portanto o recurso de dizer das nossas expedições armadas por esses domínios. Só à noite enxergamos claro. (HOLANDA, 2005, p. 215)
\end{abstract}

A afinidade do autor com o surrealismo manifesta-se com todo vigor nessas palavras assertivas, na convicção de que o sonho era uma poderosa e libertadora ferramenta artística. Para além de uma concepção estética, a afirmação das potencialidades oníricas também expressava princípios pessoais, coerentes com sua atitude de insubmissão às normas e às regras, de insatisfação com a realidade e de compromisso com a quebra de certas amarras que embaraçavam a experiência humana.

A declarada intenção de explorar esses "domínios" desconhecidos, através de "expedições armadas", nos remete à passagem do "Manifesto do Surrealismo" (1924) em que Breton refere-se à descoberta de Freud:

Na trilha de suas descobertas, esboça-se, enfim, uma corrente de opinião, a favor da qual o explorador humano poderá levar mais longe suas investigações, autorizado que estará a não mais levar em conta realidades sumárias. A imaginação está talvez a ponto de retomar seus direitos. (BRETON, 2012, p. 226)

O interesse pela noite impulsionava essa vontade expedicionária. Ao escrever que "só à noite enxergamos claro", Sérgio Buarque sublinha sua confiança na capacidade reveladora dos sonhos, considerando-os como meios fundamentais de compreensão. Sentido que podemos estender à sua proximidade com o surrealismo, encarado não como uma escola artística, "mas como um meio de conhecimento, particularmente de continentes que até então não haviam sido explorados" (NADEAU, 2008, p.46).

A declaração dos direitos do sonho reivindicada por Buarque de Holanda evidencia de maneira indisfarçável sua adesão àquela que talvez seja a mais marcante proposta surrealista. Como esclareceu Robert Ponge, a frase sinalizava o contato do autor com outra fonte de leitura ${ }^{13}$, revelando o convívio ativo e substancioso com as ideias e textos produzidos pelo grupo liderado por Breton.

No primeiro número da revista La Révolution Surréaliste (1924-1929), de $1^{\circ}$ de dezembro de 1924, lia-se na capa os seguintes dizeres, referentes ao título da publicação: "Il faut aboutir a une nouvelle déclaration des droits de l'homme" (LA RÉVOLUTION SURRÉALISTE, 1975). A revolução surrealista, de acordo com a leitura proposta pelo jogo gráfico feito na capa, deveria levar a uma nova declaração dos direitos do homem.

Seguindo a interpretação sugerida por Robert Ponge para a frase, vemos que o autor de "Perspectivas" aproveita-se da divisa estampada na capa da revista na composição de sua "declaração dos direitos do Sonho", modificando-a, entretanto, ao substituir significativamente a palavra homem por sonho.

Com essa sutil alteração, Sérgio Buarque jogava com as ideias propostas pela própria revista francesa, mais precisamente com aquelas expressas no prefácio, assinado por Jacques-

\footnotetext{
13 Robert Ponge, estudando os "primeiríssimos contatos" do Brasil com o surrealismo, aponta os editores de Estética como os intelectuais daquele momento que foram mais sensíveis ao surrealismo, fazendo ressonância as suas propostas. Ao comentar algumas das ideias surrealistas presentes em "Perspectivas" (1925), de Sérgio Buarque, Ponge revela as leituras que estão na base da declaração de direitos do sonho do jovem autor: "A atitude de Sérgio Buarque de Holanda é curiosa e merece reter nossa atenção: ao falar numa declaração dos direitos do sonho, o autor joga com o prefácio e com o lema da capa do primeiro número de La Révolution Surréaliste, fazendo uma colagem de ambos, mas sem dizê-lo e sem formular uma única vez a palavra surrealista (ou supra-realista, como se usava então)." (PONGE, 2004, p. 56).
} 
André Boiffard (1902-1961), Paul Éluard (1895-1952) e Roger Vitrac (1899-1952). Nele, os autores criticavam o conhecimento racional e realista, ao mesmo tempo em que elogiavam as potencialidades do sonho, esse "tyran terrible habillé de miroirs et d'éclairs", que restituía ao homem todos os seus direitos à liberdade ${ }^{14}$.

A afirmação do sonho mostra que nosso autor acreditava, assim como os surrealistas, no acesso às experiências mais profundas do ser humano e, sobretudo, na possibilidade de expressálas artisticamente. O jovem ensaísta recusava-se a aceitar as impossibilidades sugeridas na “admirável" passagem de Marcel Proust (1871-1922), citada como um contraponto argumentativo à reivindicação que propunha:

[Na música de Vinteuil, havia assim dessas] visões que é impossível exprimir e quase proibido constatar, porquanto, quando no momento de adormecer recebemos a carícia do seu irreal encantamento, no momento mesmo em que a razão já nos abandonou, os olhos se fecham e antes de termos tido tempo de conhecer não só o inefável mas o invisível, adormecemos. (PROUST, 2011, p. 432)

As visões desconhecidas referidas por Proust surgiam ao homem no estágio onde a consciência vacila, onde ele encontra-se na incerta fronteira entre a vigília e o sono. Diante da hesitação que o romancista francês expressava com relação à oportunidade de alcançar os mistérios e encantos de tais experiências - porta de entrada para as regiões do sonho -, Sérgio Buarque perguntava-se: "Mas de que nos vale a confiança no milagre se não ousamos transpor aquele impossivel e aquele proibido colocados ali por prudência ou por covardia?" (HOLANDA, 2005, p. 216).

A revolta de Buarque de Holanda com relação às formas de representação é notória, permeando o tom categórico e incisivo de seu ensaio. Cifrada em um texto que possui a verve de um manifesto, ela pode ser interpretada no desabafo e nas críticas de quem sentia, com pesar mas sem resignação, que a fixação do real constituía uma perda de contato com o princípio de vida, que se manifestava nos elementos e nas coisas do mundo.

A mais cortante expressão dessa acentuada descrença revela-se, talvez, no parágrafo de abertura de "Perspectivas", quando o autor escreve:

As palavras depositaram tamanha desconfiança no espírito crédulo dos homens, que
estes acabaram por lhes voltar as costas. A gente começa a admirar-se de que uma
porção de civilizações tenha enxergado incessantemente na letra qualquer cousa que
não seja uma negação de vida - negação formal, está claro, mas nem por isso menos
eficiente. (HOLANDA, 2005, p. 214) (15 $^{15}$

Voltando-se para a questão da linguagem, e tendo em vista que "nada do que vive se exprime impunemente em vocábulos”, Sérgio Buarque de Holanda substancia a convicção de que há uma oposição entre vida e representação na crítica à palavra e no ataque à "falsa paz que as letras impuseram"(HOLANDA, 2005, p. 214-215).

${ }^{14}$ No início do prefácio, os autores escrevem: “Le procès de la connaissance n'étant plus à faire, l'intelligence n' entrant plus en ligne de compte, le rêve seul laisse à l'homme tous ses droits à la liberté.". BOIFFARD, JecquesAndré; ÉLUARD, Paul; VITRAC, Roger. "Preface" in: La Révolution Surréaliste: colection complète 1924-1929. Paris: Jean-Michel Place, 1975, p. 1. Agradeço a gentileza e a generosidade de Lucas Santiago Rodrigues De Nicola e João Ivo Dapieve Miranda Pinheiro Duarte Guimarães, que traduziram, a meu pedido, o prefácio que ora citamos.

15 Anotemos, de passagem, a ressonância que pode ser observada entre a célebre abertura de "Perspectivas" (1925) e o início do primeiro parágrafo do Manifesto do Surrealismo (1924), de André Breton, que dizia: "Tão longe vai a crença na vida, no que a vida tem de mais precário, a vida real entenda-se, que, por fim, esta crença se perde. O homem, este sonhador definitivo, dia a dia mais insatisfeito com sua sorte, passa em revista, a custo, os objetos de que foi levado a fazer uso, aos quais dispensou sua incúria, ou seu esforço, quase sempre seu esforço, pois que ele consentiu em trabalhar [...]" (BRETON, 2012, p. 220). 
Nesse ponto, é oportuno lembrar as importantes observações de Mariana Thiengo referentes a "Perspectivas", especialmente aquelas que têm o início do ensaio como foco. Suas colocações desvelam o diálogo de Sérgio Buarque com outro referente importante, iluminando fundamentos teóricos mobilizados pelo ensaísta na elaboração de suas reflexões.

Em sua pesquisa, a autora distingue na crítica buarqueana uma investida contra o poder redutor das palavras, movimento que procurava preservar o fluxo e a dinâmica da vida, confinada nas formas inertes e sedimentadas das letras. Esse posicionamento, que questionava a linguagem como uma das bases do conhecimento, ainda indicava uma sugestiva aproximação com o pensamento de Friedrich Nietzsche (1844-1900) (THIENGO, 2011, p. 93). Segundo Thiengo:

Trata-se de desmistificar a crença no poder da linguagem - reduto kantiano da razão como instância que garante o acesso ao conhecimento do mundo. Melhor: trata-se de negar a linguagem como instância abstrata, separada de outras dimensões da existência, numa evidente crítica ao conhecimento de base idealista, que se quer engendrado a partir de uma desvinculação com as bases materiais da existência [...] (THIENGO, 2011, p. 94)

Confrontando as ideias de Buarque de Holanda com aquelas propostas por Nietzsche, Thiengo assinala a notável semelhança do início de "Perspectivas" com o seguinte trecho do fragmento número 11 de Humano, demasiado bumano (1886): A importância da linguagem para o desenvolvimento da cultura está em que nela o
homem estabeleceu um mundo próprio ao lodo de outro, um lugar que ele considerou
firme o bastante para, a partir dele, tirar dos eixos o mundo restante e se tornar seu
senhor. Na medida em que por muito tempo acreditou nos conceitos e nomes de coisas
como em aeternae veritates [verdades eternas], o homem adquiriu esse orgulho com
que se ergue acima do animal: pensou ter realmente na linguagem o conhecimento do
mundo. O criador da linguagem não foi modesto a ponto de crer que dava às coisas
apenas denominações, ele imaginou, isto sim, exprimir com as palavras o supremo
saber sobre as coisas: de fato, a linguagem é a primeira etapa no esforço da ciência.
(NIETZSCHE, 2000, p. 21 )

Sérgio Buarque de Holanda, ao denunciar a arbitrariedade e a falsidade do mundo criado pelas representações humanas, acima de tudo por aquelas engendradas pela linguagem, mostravase informado pelo pensamento nietzschiano.

O perspectivismo de Nietzsche, no qual a atitude crítica de nosso autor se alicerçava, pressupunha uma visão em que o mundo é compreendido na sua infinidade de pontos de vista, "na medida em que não podemos rejeitar a possibilidade de que ele encerre infinitas interpretaçoes". No entender do autor de A gaia ciência (1882), seria uma "imodéstia" sentenciar que o ângulo no qual observamos determinado aspecto, era o único em que se poderiam ter perspectivas, desconsiderando a validade e multiplicidade de outras posições que enfocassem o mesmo problema ${ }^{16}$.

Há que se dizer que se nós nos aprofundarmos nas convergências entre as posturas questionadoras dos dois autores, perseguindo o alcance e a extensão da influência das ideias de Nietzsche na concepção de "Perspectivas", seríamos direcionados para a crítica ao conhecimento e à verdade formulada pelo filósofo alemão, caminhos que escapam aos nossos propósitos.

Porém, não podemos deixar de anotar que a concepção nietzschiana de que "a vida é composta de aparência, erro, embuste, simulação, cegamento, autocegamento" (NIETZSCHE, 2001, p. 236), está nas proximidades daquela que se coloca no horizonte do ensaio de Sérgio Buarque de Holanda. Toda forma de conhecimento, ao tentar apreender a vida, procura pôr em

16 As citações e as ideias desse parágrafo estão todas em: NIETZSCHE, Friedrich. A gaia ciência. São Paulo: Companhia das Letras, 2001, p. 278. 
paz aquilo que só é domesticável com um empenho arbitrário, com um esforço de "simplificação e falsificação".

Buarque de Holanda possuía uma clara noção de que havia nas "cousas" uma instabilidade que era preciso respeitar, avaliada por ele, aliás, como uma condição de vida peculiar a elas (HOLANDA, 2005, p. 214). A partir dessa percepção, considerava a flexibilidade necessária a um pensamento filosófico para debruçar-se sobre a realidade e existência das coisas, captando o que nelas havia de imprevisto e que escapava à lógica da continuidade (HOLANDA, 2005, p. 216).

Assim, através desses critérios, censurava os sábios que, para pensar com amplitude, "sacrificavam" tudo aquilo que se "exalta e afirma" pela diferença, que se distinguia pela singularidade (HOLANDA, 2005, p. 216). Não espanta que, nesse ponto de sua investida contra o conhecimento, o jovem ensaísta chegue à crítica à ciência justamente pela exigência de uma atenção ao particular:

A ciência compraz-se em estabelecer um nivelamento, uma uniformidade tal em todas as cousas, que acaba por excluir de seu universo qualquer objeto que não se resigne a ser simples termo para as suas equações, um instrumento dócil às suas construções arbitrárias. $\mathrm{O}$ ato elementar de definir, que se encontra à base de toda ciência humana, implica o propósito de instalar todo objeto de conhecimento numa continuidade fixa e inalterável. (HOLANDA, 2005, p. 216)

Se lembrarmos das últimas considerações do fragmento de Friedrich Nietzsche que citamos mais acima, em que as semelhanças com o trecho de abertura de "Perspectivas" são evidentes, veremos que a crítica à ciência tem raízes na crítica à linguagem. Ao criá-la, o homem não conferia apenas nomes às coisas, mas pensava ter na linguagem o conhecimento do mundo, acreditando nos conceitos e denominações como verdades eternas. À vista disso, Nietzsche considerava que "a linguagem é a primeira etapa no esforço da ciência" (NIETZSCHE, 2000, p. 21).

Em "Perspectivas", as críticas de Sérgio Buarque de Holanda estão cifradas em um textomanifesto que explora as potencialidades poéticas da prosa ensaística, revelando suas "perspectivas" mais caras à época. Entre elas, é possível distinguir duas das mais intensas, que fecundam de maneira mais vigorosa o ideário crítico do ensaio: o surrealismo, encarado como proposta que oferecia instrumentos de investigação e entendimento da experiência humana, e o pensamento nietzschiano, que proporcionava ângulos reflexivos questionadores para o jovem e inquieto escritor.

Tendo em vista a confluência desses dois elementos que contribuem para fundamentar o ensaio buarqueano, podemos arriscar uma hipótese, baseada nas próprias ideias de Friedrich Nietzsche, que possivelmente agradaria ao autor de "Perspectivas".

Em alguns momentos de suas reflexões, o filósofo alemão expressou o desejo de promover uma coerência e uma ligação entre os conhecimentos (NIETSCHE, 2001, p. 92), de criar um pensamento que não opusesse arte e ciência, mas que possibilitasse a união entre elas. É provável que o jovem editor de Estética fosse sensível à ideia, em especial diante do seu desagrado com relação à distância entre conhecimento e vida. O horizonte projetado pelo autor de Genealogia da moral (1887) prefigurava um tempo em que:

[...] as forças artísticas e a sabedoria prática da vida se juntarão ao pensamento científico, em que se formará um sistema orgânico mais elevado, em relação ao qual o erudito, o médico, o artista e o legislador, tal como agora os conhecemos, pareceriam pobres antiguidades. (NIETZSCHE, 2001, p. 141)

Se tal expectativa se realizasse, seria lícito esperar que o homem atingisse algumas das regiões mais ocultas a que Sérgio Buarque de Holanda se refere. Ele não mais precisaria opor 
uma "eficaz" e "absurda" resistência aos segredos e aos mistérios da vida, nem renunciar a ela para descobrir o "irreal" (HOLANDA, 2005, p. 217-218). Nessa conjectura, talvez os homens pudessem retomar sua condição de sujeitos ativos diante das palavras, sem precisar voltar às costas a elas - então destituídas de capacidade de ação, não mais personificadas -, voltando a poder confiar na linguagem como uma representação não legítima, mas admissível da vida.

\section{Jovem crítico, crítica madura}

Através dos textos de Sérgio Buarque de Holanda publicados em Estética - em especial o ensaio "Perspectivas" - é possível identificar um perceptível desenvolvimento em suas reflexões e comentários, que se mostram mais densos e aprofundados. Ademais, há um aguçamento de uma atitude substancialmente crítica, que passa a nutrir suas apreciações e juízos. Ajustando sua pena a essa conduta questionadora, o jovem escritor passa em vista alguns dos rumos percorridos pelo modernismo brasileiro até aquele momento, extravasando, inclusive, os limites das questões circunscritas ao âmbito do "nacional".

Das considerações elogiosas feitas à Graça Aranha em "Um homem essencial", publicado no primeiro número de Estética, em que a revista deixava ver certo "protesto de consideração" 17 ao autor de Canaã, às espessas e cifradas meditações do ensaio "Perspectivas", impresso na última edição do periódico carioca, há um sensível amadurecimento do jovem crítico literário. Percebese na evolução dessas produções uma confiança maior em suas avaliações, um aprimoramento de seus instrumentos de análise que, paralelamente, acompanhava a posição de maior relevo que adquirira dentro do modernismo.

A revista que editou com Prudente de Moraes, neto, de certa forma, seguiu esse progresso, acompanhando o amolar da navalha crítica de seus jovens editores. À revelia das várias contribuições com que uma revista literária é composta, que naturalmente fazia com que elas tendessem para uma proposta por vezes dispersiva e pouco coesa, dissolvida na multiplicidade de colaboradores, Estética foi sensível às intenções de seus idealizadores.

Como lembrou o próprio Prudente, a publicação que dirigiu com o amigo pretendera discutir "os problemas ante os quais seus colaboradores pudessem situar-se diversamente", buscando a superação de espíritos sectários a partir de uma postura crítica timbrada pela independência e pela transparência de opiniões (DANTAS, 1974, p. XII).

Sérgio Buarque de Holanda, corroborando tal anseio, apontou que os editores de Estética "queriam dizer à vontade o que pensavam", espírito que deveria ser compartilhado com os participantes da revista. Não à toa, ela fora idealizada como órgão reflexivo, que buscava apresentar-se com um "aspecto de estudo" (LEONEL, 1984b, p. 171). Podemos supor, inclusive, que essa intensão tenha se refletido nos aspectos visuais da revista, que não apenas revelariam as limitações financeiras do empreendimento, mas também a expressão gráfica da vocação para à análise que ambos buscaram imprimir no periódico que fundaram.

No entanto, a experiência da sinceridade crítica não rendeu bons resultados para Sérgio Buarque, em particular quanto aos seus pares "revolucionários". A inovação possuía um limite; a rebeldia resvalava e, às vezes, estacava na individualidade. A publicação da revista Estética, principal veículo do movimento em 1924-1925, demonstrara claros indícios das limitações dessa orientação franca e transparente.

Tendo em vista que os periódicos conservam uma sensibilidade ímpar no que toca ao ambiente literário no qual aparecem, o caso da revista carioca não foi diferente. Os três números editados evidenciaram progressivos estremecimentos, gretas que riscavam o terreno conquistado,

17 A expressão é de Maria Célia de Moraes Leonel. Ao discordar da opinião de Mário de Andrade de que o primeiro número de Estética era muito mais de homenagem à Graça Aranha do que o último número de Klaxon, a autora escreve: "O número em questão de Estética não deixa de ser, entretanto, pelo menos um protesto de consideração" (LEONEL, 1984a, p. 50). 
talhando o bloco até então unitário. Significativamente, o primeiro número abre-se com o elogio esperançoso à juventude moderna, de autoria de Graça Aranha; o terceiro fecha-se com a viperina "Carta aberta a Alberto de Oliveira", de Mário de Andrade, onde este questiona, entre outras coisas, o modernismo de Graça Aranha.

Estética foi desconfortável. Em grande medida, a responsabilidade pelo mal-estar pode ser creditada à orientação que os diretores imprimiram à revista, que tinha na sinceridade o critério elementar para o arrojado empreendimento autocrítico. Em suas páginas, não há vestígios de uma imposição explícita quanto a esta diretriz, mas percebe-se uma tácita acomodação com relação a ela, levando alguns de seus colaboradores ao salutar e oscilante exercício do comentário desassombrado. No caso de Buarque de Holanda, tal premissa permitiu, inclusive, o então inusitado namoro com a noite surrealista e a crítica nietzschiana, alicerces críticos que revelavam posições pessoais do jovem intelectual. Se haveria que pautar-se pela sinceridade, por que não deixar emergir a lucidez crítica vinda dos recônditos escuros? Afinal, só à noite enxergamos claro.

\section{REFERÊNCIAS BIBLIOGRÁFICAS}

Klaxon: Mensário de Arte Moderna. São Paulo: Imprensa Oficial do Estado de São Paulo, Biblioteca Brasiliana Guita e José Mindlin, 2014.

La Révolution Surréaliste: colection complète 1924-1929. Paris: Jean-Michel Place, 1975.

ANDRADE, Rodrigo Melo Franco de. "Graça Aranha - O Espirito Moderno" in: Estética - Edição fac-similar. São Paulo: Imprensa Oficial do Estado de São Paulo, Biblioteca Brasiliana Guita e José Mindlin, 2014, p. 295. (n³, abril-junho de 1925).

BARROS, A. C. Couto de. "A extraordinária história da mulher que se tornou infinita" [Klaxon, no 8-9, dezembro de 1922 - janeira de 1923] in: Klaxon: Mensário de Arte Moderna. São Paulo: Imprensa Oficial do Estado de São Paulo, Biblioteca Brasiliana Guita e José Mindlin, 2014, p. 20 21.

BRETON, André. "Manifesto do Surrealismo" in: TELES, Gilberto Mendonça. Vanguarda europeia e modernismo brasileiro: apresentação dos principais poemas metalinguísticos, manifestos, prefácios e conferências vanguardistas, de 1857 a 1972. 20 ed. Rio de Janeiro: José Olympio, 2012, p. 220-260.

DANTAS, Pedro. "Vida da estética e não estética da vida" in: Estética: 1924/1925. Rio de Janeiro: Gernasa, 1974.

EUGÊNIO, João Kennedy. "Um horizonte de autenticidade: Sérgio Buarque de Holanda: monarquista, modernista, romântico (1920-1935)" in: Sérgio Buarque de Holanda: perspectivas. Organização: Pedro Meira Monteiro e João Kennedy Eugêncio. Campinas, SP: Editora da UNICAMP; Rio de Janeiro: EdUERJ, 2008, p. 425-459.

FACIOLI, Valentin. "Modernismo, vanguardas e surrealismo no Brasil" in: Surrealismo e Novo Mundo. Porto Alegre: Editora da Universidade/ UFRGS, 1999, p. 293-307.

FACCHINETTI, Cristiana. "Psicanálise Modernista no Brasil: um Recorte Histórico" in: PHYSIS: Revista de Saúde Coletiva. Rio de Janeiro, vol. 13, n. 1, junho de 2003, p. 115-137.

HOLANDA, Sérgio Buarque de. "Antinous (fragmento)" [Klaxon, $\mathrm{n}^{\circ}$ 4, 15 de agosto de 1922] in: Klaxon: Mensário de Arte Moderna. São Paulo: Imprensa Oficial do Estado de São Paulo, Biblioteca Brasiliana Guita e José Mindlin, 2014, p. 1-2. 
HOLANDA, Sérgio Buarque de. "Perspectivas" in: O Espirito e a Letra: estudos de crítica literária I, 1920-1947. São Paulo: Companhia das Letras, 2005, p. 214-218.

LARA, Cecília. Klaxon \& Terra Roxa e outras terras: dois periódicos modernistas de São Paulo. São Paulo: Instituto de Estudos Brasileiros, 1972.

LEONEL, Maria Célia de Moraes. Estética e modernismo. São Paulo: HUCITEC; Brasília: INL, Fundação Nacional Pró-Memória, 1984a.

LEONEL, Maria Célia de Moraes. "Entrevista com Sérgio Buarque de Holanda" in: Estética e modernismo. São Paulo: HUCITEC; Brasília: INL, Fundação Nacional Pró-Memória, 1984b, p. 171-180.

LIMA, Sérgio Claudio de Franceschi. Surrealismo - Polêmica de sua recep̧̣ão no Brasil modernista. Tese (Doutorado). Faculdade de Filosofia, Letras e Ciências Humanas, Universidade de São Paulo. São Paulo, 1998.

MORAES, Prudente de. "Sobre a sinceridade" in: Klaxon: Mensário de Arte Moderna. Organização: Pedro Puntoni e Samuel Tintan Jr. Ensaio: Gênese de Andrade. São Paulo: Imprensa Oficial do Estado de São Paulo, Biblioteca Brasiliana Guita e José Mindlin, 2014, p. 159-164. [Estética n 2, janeiro-março de 1925].

MORAES, Rubens Borba. Domingo dos séculos (ed. fac-similada). São Paulo: Imprensa Oficial, 2001.

NADEAU, Maurice. História do surrealismo. São Paulo: Perspectiva, 2008.

PINTO, Virgílio Noya. "Antecedentes da Semana de Arte Moderna" in: Anais do curso "A Semana de Arte Moderna de 22, sessenta anos depois". São Paulo: Secretaria de Estado da Cultura, 1984, p. 1924.

NIETZSCHE, Friedrich. Humano, demasiado bumano: um livro para espíritos livres. São Paulo: Companhia das Letras, 2000.

NIETZSCHE, Friedrich. A gaia ciência. São Paulo: Companhia das Letras, 2001.

PONGE, Robert. "Notas sobre a recepção e presença do surrealismo no Brasil nos anos 19201950" in: Alea: Estudos Neolatinos. Rio de Janeiro, vol. 6, n 1, janeiro-junho 2004, p. 53-65.

PROUST, Marcel. A prisioneira. Tradução de Manuel Bandeira e Lourdes Sousa de Alencar. São Paulo, Globo, 2011.

RAYMOND, Marcel. "O surrealismo” in: De Baudelaire ao Surrealismo. São Paulo: Editora da Universidade de São Paulo, 1997.

THIENGO, Mariana. A crítica entre a literatura e a história: o percurso da crítica literária de Sérgio Buarque de Holanda dos verdes anos à profissionalização do ofício. Tese (Doutorado). Universidade Federal de Minas Gerais, Faculdade de Letras. Minas Gerais, 2011.

Recebido em 24/02/2017

Aceito em 14/06/2017

Publicado em 26/06/2017 